\title{
The role of poly(ADP-ribose) in the DNA damage signaling network
}

\author{
Malanga, M ; Althaus, F R
}

\begin{abstract}
DNA damage signaling is crucial for the maintenance of genome integrity. In higher eukaryotes a NAD+-dependent signal transduction mechanism has evolved to protect cells against the genome destabilizing effects of DNA strand breaks. The mechanism involves 2 nuclear enzymes that sense DNA strand breaks, poly(ADP-ribose) polymerase-1 and -2 (PARP-1 and PARP-2). When activated by DNA breaks, these PARPs use NAD + to catalyze their automodification with negatively charged, long and branched ADP-ribose polymers. Through recruitment of specific proteins at the site of damage and regulation of their activities, these polymers may either directly participate in the repair process or coordinate repair through chromatin unfolding, cell cycle progression, and cell survival-cell death pathways. A number of proteins, including histones, DNA topoisomerases, DNA methyltransferase-1 as well as DNA damage repair and checkpoint proteins (p23, p21, DNA-PK, NF-kB, XRCC1, and others) can be targeted in this manner; the interaction involves a specific poly(ADP-ribose)-binding sequence motif of 20-26 amino acids in the target domains.
\end{abstract}

DOI: https://doi.org/10.1139/O05-038

Posted at the Zurich Open Repository and Archive, University of Zurich ZORA URL: https://doi.org/10.5167/uzh-5838

Journal Article

Originally published at:

Malanga, M; Althaus, F R (2005). The role of poly(ADP-ribose) in the DNA damage signaling network. Biochemistry and Cell Biology, 83(3):354-364.

DOI: https://doi.org/10.1139/O05-038 


\title{
The role of poly(ADP-ribose) in the DNA damage signaling network ${ }^{1}$
}

\author{
Maria Malanga and Felix R. Althaus
}

\begin{abstract}
DNA damage signaling is crucial for the maintenance of genome integrity. In higher eukaryotes a NAD ${ }^{+}$ dependent signal transduction mechanism has evolved to protect cells against the genome destabilizing effects of DNA strand breaks. The mechanism involves 2 nuclear enzymes that sense DNA strand breaks, poly(ADP-ribose) polymerase-1 and -2 (PARP-1 and PARP-2). When activated by DNA breaks, these PARPs use NAD ${ }^{+}$to catalyze their automodification with negatively charged, long and branched ADP-ribose polymers. Through recruitment of specific proteins at the site of damage and regulation of their activities, these polymers may either directly participate in the repair process or coordinate repair through chromatin unfolding, cell cycle progression, and cell survival - cell death pathways. A number of proteins, including histones, DNA topoisomerases, DNA methyltransferase-1 as well as DNA damage repair and checkpoint proteins (p23, p21, DNA-PK, NF-kB, XRCC1, and others) can be targeted in this manner; the interaction involves a specific poly(ADP-ribose)-binding sequence motif of 20-26 amino acids in the target domains.
\end{abstract}

Key words: PARP; polymer binding; non-covalent interaction; p53; DNA topoisomerase I.

Résumé : La signalisation relative aux dommages à l'ADN est cruciale au maintien de l'intégrité du génome. Un mécanisme de transduction dépendant du $\mathrm{NAD}^{+} \mathrm{s}^{\prime}$ est développé chez les eucaryotes supérieurs afin de protéger les cellules contre les effets déstabilisants des bris à l'ADN. Ce mécanisme implique deux enzymes jouant le rôle de senseur de bris à 1'ADN, les poly (ADP-ribose) polymérase-1- et -2 (PARP-1 et PARP-2). Lorsque activées par des bris à l'ADN, ces PARP utilisent le $\mathrm{NAD}^{+}$pour catalyser leur propre auto-modification par des polymères négativement chargés d'ADP-ribose longs et branchés. À travers le recrutement de protéines spécifiques au site de dommage et par la régulation de leur activité, ces polymères peuvent soit participer directement au processus de réparation, soit coordonner la réparation impliquant le déroulement de l'ADN, la progression du cycle cellulaire ainsi que les sentiers de survie ou de mort des cellules. Un certain nombre de protéines incluant les histones, les topoisomérases d'ADN, la méthyltransférase-1 d'ADN, ainsi que les protéines de réparation d'ADN et les protéines de points de contrôle (p23, p21, ADN-PK, NF-kB, XRCC1 et autres) peuvent être ciblées de cette manière, cette interaction impliquant un motif de liaison de poly (ADP-ribose) spécifique de 20-26 acides aminés présent sur les domaines cibles.

Mots clés : PARP; liaison des polymères; interactions non covalentes; p53; ADN topoisomérase I.

[Traduit par la Rédaction]

\section{Introduction}

The structural integrity of the chromosomes is maintained by checkpoint pathways protecting cells and organisms from functional disturbances in DNA and cell cycling (Kastan and Bartek 2004). Checkpoint activation involves recognition of

Received 14 December 2004. Revision received 8 February 2005 Accepted 15 February 2005. Published on the NRC Research Press Web site at http://bcb.nrc.ca on 14 June 2005.

M. Malanga and F.R. Althaus. ${ }^{2}$ Institute of Pharmacology and Toxicology, University of Zurich-Tierspital,

Winterthurerstrasse 260, CH-8057 Zurich, Switzerland

${ }^{1}$ This article is one of a selection of papers in this Special Issue, entitled Epigenetics in Chromatin, and has undergone the Journal's regular peer review process.

${ }^{2}$ Corresponding author (e-mail: fra@ vetpharm.unizh.ch). the cause and signal transduction to downstream effectors, which control DNA damage processing, cell cycle progression, and cell death programs. In higher eukaryotes, DNA strand breaks, either generated directly by ionizing radiation and oxidizing agents or arising as intermediates of repair processes, are sensed by an abundant, 116-kDa nuclear enzyme, poly(ADP-ribose) polymerase-1 (PARP-1) (de Murcia and Menissier-de Murcia 1994). This is a member of a large family of enzymes with a homologous catalytic domain but with otherwise distinct structures, functions, and localizations (Amé et al. 2004). PARP-1 binds with high affinity to DNA strand interruptions via $2 \mathrm{~N}$-terminal zinc finger modules, with consequent activation of its catalytic C-terminal domain. Activated PARP-1 uses $\mathrm{NAD}^{+}$as a substrate to catalyze its automodification as a homodimer (MendozaAlvarez and Alvarez-Gonzalez 1993; Panzeter and Althaus 1994) and, to a lesser extent, the modification of other nuclear proteins, with ADP-ribose chains (Fig. 1). Each en- 
Fig. 1. The poly(ADP-ribosyl)ation reaction. Poly(ADP-ribose) polymerase (PARP) enzymes use NAD ${ }^{+}$as a source of ADP-ribose moieties to synthesize protein-bound linear or branched homopolymers. ADP-ribose units are linked by $\alpha\left(1^{\prime \prime}-2^{\prime}\right)$ ribosyl-ribose glycosidic bonds in the linear portions of the polymer or by $\alpha\left(1^{\prime \prime \prime}-2^{\prime \prime}\right)$ ribosyl-ribose glycosidic linkages at the branching points; their number ranges from a few to over 200 . Branching frequency is estimated to be $2 \%-3 \%$. Arrows indicate sites of attack by the polymerhydrolyzing enzyme PARG (poly(ADP-ribose) glycohydrolase).

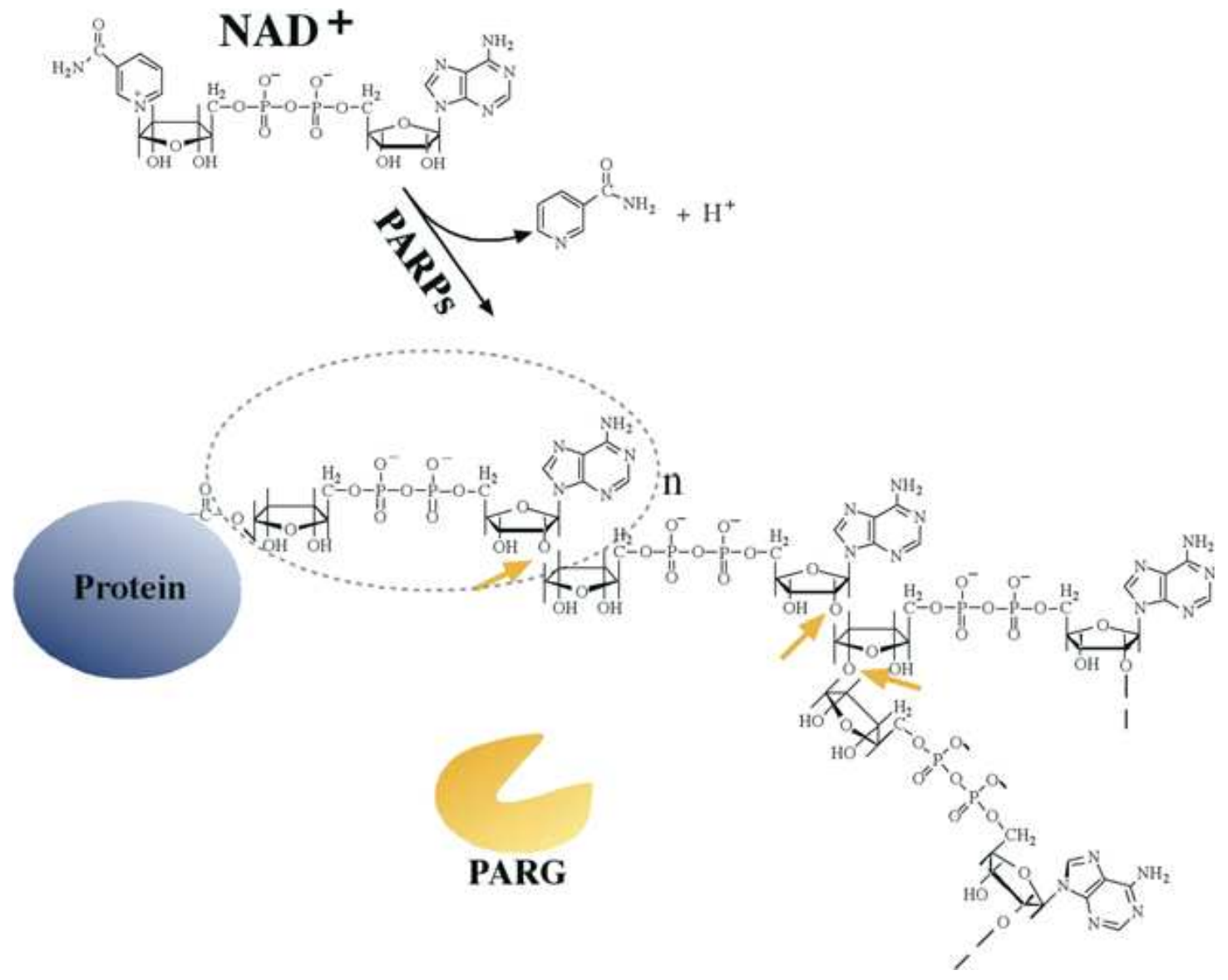

zyme molecule may carry up to 28 polymers of heterogeneous length (up to 200 ADP-ribose units) and with periodic branching (D'Amours et al. 1999; Rolli et al. 2000).

Another nuclear member of the PARP family, PARP-2, is also able to catalyze DNA damage-dependent automodification and can homo- or hetero-dimerize with PARP-1 (Amé et al. 1999; Schreiber et al. 2002). Although PARP-2 accounts for only $10 \%-15 \%$ of the cellular poly(ADP-ribosyl)ation capacity under conditions of genotoxic stress (Amé et al. 1999), it can partially compensate for PARP-1 loss in knockout mice. Simultaneous deletion of both parp-1 and parp-2 genes is incompatible with development; embryos die at the onset of gastrulation (Ménissier-de Murcia et al. 2003).

A unique, evolutionarily conserved enzyme, poly(ADPribose) glycohydrolase (PARG) is responsible for the specific degradation of polymers to monomeric ADP-ribose units (Davidovic et al. 2001). In mammals, PARG is encoded by a single gene; however it is expressed as multiple isoforms, which arise from alternatively spliced and full-length transcripts (102 kDa, $99 \mathrm{kDa}$, and $111 \mathrm{kDa}$ proteins, respectively, in human cells) (Meyer-Ficca et al. 2004). A nuclear localization signal at the extreme $\mathrm{N}$-terminus (amino acids 10 16, in human PARG) targets the $111-\mathrm{kDa}$ isoform to the nucleus, while the lower molecular weight variants are predominantly cytoplasmic (Meyer-Ficca et al. 2004).

Although present in the cells at low abundancy, PARG has a high specific activity and acts in concert with PARPs to maintain intracellular poly(ADP-ribose) levels at very low concentrations under homeostatic conditions (Davidovic et al. 2001). The crucial importance of such a coordinated mechanism is emphasized by the recent finding that failure to degrade poly(ADP-ribose) in PARG knockout mice causes early embryonic lethality (Koh et al. 2004). Moreover, embryonic trophoblast stem cells from these mice accumulate poly(ADP-ribose) and undergo cell death unless cultured in the presence of PARP inhibitors (Koh et al. 2004).

In DNA-damaged cells, increased poly(ADP-ribose) synthesis due to PARP-1 and PARP-2 activation is paralleled by an accelerated catabolism that reduces polymer half life from several hours to a few seconds (Alvarez-Gonzalez and Althaus 1989; Malanga and Althaus 1994). This allows rapid reversal of PARPs' automodification and ensures that elevated poly(ADP-ribose) levels are present only transiently in the cell.

Chemical or genetic disruption of PARP-1 or PARP-2 functions, as well as downregulation of PARG activity, are 
Fig. 2. Signaling of DNA strand breaks by the PARP/PARG system. PARP-1 and PARP-2 (here both designated PARP) bind to DNA strand breaks and form a catalytically active dimer; nicked DNA is stabilized in a V-shaped conformation (Le Cam et al. 1994). Activated PARPs catalyze their own modification with an array of long and branched ADP-ribose polymers (PAR). These polymers bind specific proteins (e.g., XRCC1, DNA ligase III, p53, DNA-PK) and modulate their functions, thus affecting the repair process as well as pathways controlling downstream responses to DNA damage (i.e., cell cycle progression, cell death). Finally, polymer-bound proteins are released upon polymer degradation by PARG.

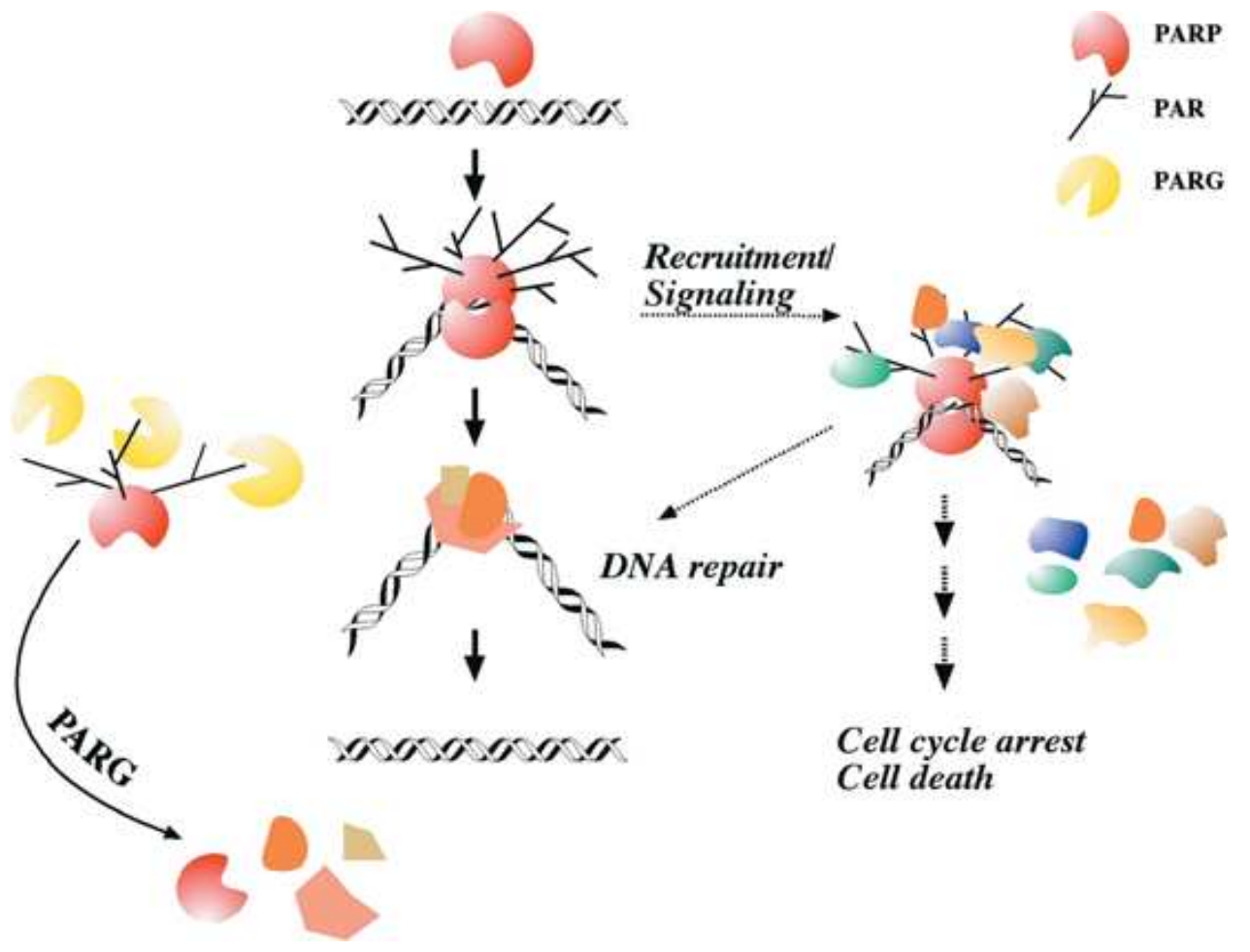

associated with reduced DNA repair capacity, hypersensitivity to genotoxic agents, and higher genomic instability (Shall and de Murcia 2000; Masutani et al. 2000; Menissier-de Murcia et al. 2003; Cortes et al. 2004). In fact, PARP-1 and PARP-2 participate in DNA base excision repair (BER) (Dantzer et al. 2000; Schreiber et al. 2002; Le Page et al. 2003) and in DNA damage signaling to cell survival - cell death pathways (Bouchard et al. 2003).

How does poly(ADP-ribose) metabolism relate to the cell's ability to cope with a genotoxic insult? While a number of different mechanisms have been implicated (D'Amours et al. 1999; Chiarugi 2002; Hassa and Hottiger 2002; Kraus and Lis 2003; Hong et al. 2004; Scovassi 2004), we focus here on the automodification reaction of PARP-1 and PARP-2. We describe how, with their long polymeric arms, these PARPs may directly recruit a specific array of proteins to sites of DNA strand breaks and transiently reprogram their domain functions. After the breaks are removed, these proteins are released and continue to function as before.

\section{DNA damage signaling by activated PARPs}

The PARP-PARG system operates as a mechanism signaling DNA strand breaks in which PARP-1 and PARP-2 play a dual role as damage sensors and signal transducers to downstream effectors (Althaus et al. 1999) (Fig. 2). In the first step, PARP-1 binding to DNA strand breaks leads to a more than 500-fold stimulation of its catalytic activity (Simonin et al. 1993); thus the original signal (i.e., the lesion on DNA) is translated (and amplified) into an array of protein-bound ADP-ribose polymers. Poly(ADP-ribosyl)ated PARP-1 dissociates from DNA (Zahradka and Ebisuzaki 1982), but it remains in the vicinity of the break site (Okano et al. 2003; El-Khamisy et al. 2003), where it creates a cluster of negative charges. Then, automodified PARPs relay the signal to effector pathways by recruiting selected proteins into multiprotein complexes and by reprogramming their functions. These proteins may either directly participate in BER or coordinate repair through chromatin unfolding, cell cycle progression, and cell death pathways (Realini and Althaus 1992; Malanga et al. 1998c; Pleschke et al. 2000; Okano et al. 2003; El-Khamisy et al. 2003; Malanga and Althaus 2004).

The relative affinity and local availability of protein partners, as well as the extent of DNA damage, may determine the type of response and the signaling outcome. For instance, PARP-1 automodification may allow the rapid assembly of the BER complex as a primary response to the DNA strand breaks, and then recruit downstream effectors to direct cells towards cell cycle arrest, followed by either repair or cell death. In addition, PARP-1 activity may alter chromatin architecture locally in a way that makes the damaged DNA more accessible to repair machineries and (or) to transcriptional regulators of the cellular response to genotoxic stress.

Finally, once the lesion has been removed, signal termina- 
tion ensues from polymer degradation by PARG. This enzyme disengages poly(ADP-ribose)-bound proteins and reverses the automodification status of PARP-1 and PARP-2, which are now ready for a new round of DNA strand break binding.

\section{Recruitment of repair machineries}

Repair of single-strand breaks by BER involves a coordinated series of events in which the protein XRCC1 (X-ray repair cross-complementing protein 1), recruited to the injured sites, operates as a scaffold that interacts with and stimulates the activity of enzymatic components of the BER machinery (Caldecott 2003). XRCC1 interacts with PARP-1 and PARP-2, and these interactions are enhanced when the 2 enzymes are in their (ADP-ribosyl)ated state (Masson et al. 1998; Schreiber et al. 2002). Another player of the BER pathway, DNA ligase III, also binds to poly(ADP-ribosyl)ated PARP-1, and after cell exposure to an oxidizing agent can be immunoprecipitated from HeLa cell extracts with anti-poly(ADP-ribose) antibodies in a complex including PARP-1 and XRCC1 (Leppard et al. 2003). Such a complex is not found when PARP-1 automodification is prevented by previous treatment with specific inhibitors. Thus, in the sequence of events of DNA damage processing, PARP-1 and PARP-2 activation precedes, and is required for, the rapid assembly of the BER machinery.

That the PARP-PARG system may actually regulate protein association dynamics at the site of DNA damage in vivo is further supported by recent studies by Okano et al. (2003) and El-Khamisy et al. (2003), demonstrating rapid recruitment of XRCC1 to sites of poly(ADP-ribose) formation in DNA-damaged living cells. Polymer synthesis and recruitment were detectable within a few minutes, followed similar kinetics, and were abrogated by chemical or genetic inactivation of PARP-1. Moreover, XRCC1 relocation to the damaged areas and formation of repair foci were absent following mutations in the BRCT1 (breast cancer susceptibility gene 1) domain, responsible for the interaction with automodified PARPs. These results may explain the observed delay in the repair of strand breaks and hypersensitivity to alkylating agents and $\gamma$-radiation of PARP-1 knockout cells and mice (Shall and de Murcia 2000; Masutani et al. 2000).

The cellular concentrations of DNA ligase III and XRCC1 in HeLa cells are about 7 and 3 times lower, respectively, than those of PARP-1 (Leppard et al. 2003), which might set a threshold to the number of repair foci above which death programs are activated. Additionally, the accumulation of proliferating cell nuclear antigen and of the chromatin assembly factor-1 at repair foci also depends, at least in part, on PARP-1 activation (Okano et al. 2003), suggesting that poly(ADP-ribose) may also be involved in a later step of the repair process, i.e., nucleosome refolding and reconstitution of an intact chromatin structure.

Recently, Audebert et al. (2004) have demonstrated a role of PARP-1 in the repair of DNA double-strand breaks through a mechanism that relies entirely on the break-sensing potential of PARP-1, activation of poly(ADP-ribose) synthesis, and recruitment of XRCC1/DNA ligase III to accomplish the break resealing step. This PARP-dependent DNA doublestrand break repair mechanism might operate as an alternative to the DNA-dependent protein kinase (DNA-PK)/XRCC4/DNA ligase IV-dependent, nonhomologous end-joining pathway. Evidence for the potential biological relevance of such a mechanism includes reduced kinetics of double-strand break rejoining in PARP-1 knockout cells or following chemical PARP inhibition (Audebert et al. 2004), increased cytotoxicity of PARP inhibitors in combination with DNA-PK inhibitors (Veuger et al. 2003), and accumulation of DNA doublestrand breaks following PARP inactivation, both in DNA-PK proficient and deficient cells (Veuger et al. 2004) or after overexpression of a catalytically inactive form of PARP-1 (Rudat et al. 2001).

\section{Signaling to downstream effectors}

PARP signaling beyond the damage-processing step involves interaction with and regulation of checkpoint proteins. The tumor-suppressor protein p53 exhibits high affinity for automodified PARP-1 (Malanga et al. 1998c) and is therefore a good candidate target. p53 plays a key role in transduction pathways induced by several types of cellular stress by regulating the expression of gene products that can either lead to cell cycle arrest in G1, thereby preventing the replication of DNA before the damage is repaired, or cause cell death by apoptosis (Lane and Hupp 2003). Poly(ADP-ribose) synthesis participates in p53 induction following $\gamma$-irradiation and in the expression of p53-responsive genes (i.e., mdm2, p21) as well as in p53-dependent cell cycle arrest in the G1 phase. In fact, p53 functions are impaired in cells exposed to PARP inhibitors or after deletion of the parp-1 gene (Wang et al. 1998; Valenzuela et al. 2002; Wieler et al. 2003).

Activation of the nuclear proteasome, leading to the rapid removal of oxidized histones, is another potentially important aspect of DNA damage signaling by the poly(ADPribosyl)ation system. In fact, increased degradation of oxidatively damaged histones in K562 human leukemic cells occurs within $5 \mathrm{~min}$ after induction of oxidative stress (Ullrich and Grune 2001) and depends on PARP-1 automodification and its specific interaction with the $20 \mathrm{~S}$ proteasome (Mayer-Kuckuk et al. 1999).

\section{Modulation of chromatin structure}

Because of its highly dynamic nature, PARP-1 automodification is especially suited to allow rapid structural changes in localized areas of the chromatin, such as those accompanying the response to DNA damage (EhrenhoferMurray 2004). In vitro, automodified PARP-1 attracts histones onto itself and causes the release of DNA from nucleosomal core particles (Mathis and Althaus 1987); this results in increased DNA susceptibility to nuclease attack (Realini and Althaus 1992). However, the nucleohistone structure can be restored after poly(ADP-ribose) degradation by PARG. These observations led to the histone shuttle model (Realini and Althaus 1992). This mechanism might act in vivo as a catalyst of nucleosome unfolding, by transiently displacing histones from DNA and hence facilitating DNA transactions by increasing template accessibility. In poly(ADP-ribose)-depleted cells, nucleosome unfolding accompanying the repair of bulky DNA adducts as well as removal of such lesions are severely impaired (Mathis and Althaus 1990).

PARP-1 automodification may also affect chromatin folding in another way, i.e., by regulating 5-methyl-cytosine levels 
and thus preventing DNA methylation-dependent chromatin condensation. In fact, inhibition of poly(ADP-ribose) synthesis in mammalian cells induces chromatin to adopt a more compact structure coincident with increased DNA methylation (de Capoa et al. 1999), suggesting an involvement of poly (ADP-ribosyl)ation in the maintenance of the cellular DNA methylation pattern. Indeed, automodified PARP-1 inhibits DNA methyltransferase-1 activity in vitro and can be immunoprecipitated as a complex with the methylase from HeLa cell extracts, suggesting that the association also occurs in vivo (Reale et al. 2005).

\section{Poly(ADP-ribose): active player in PARP- dependent signaling}

A reasonable understanding of how PARP-1 and PARP-2 activity may exert multiple functions in response to DNA damage has been achieved. Unlike most other protein-modifying groups, (ADP-ribose) polymers are variously sized acidic molecules, some of them containing branches (Miwa et al. 1983). The ribose-phosphate-phosphate-ribose backbone of poly(ADP-ribose) has a higher negative charge density than DNA and therefore may attract basic proteins from DNA. The helical conformation (Minaga and Kun 1983) and the branched structure of long polymers might also be involved in conferring some binding specificity. Thus, as a result of its size, structure, and physicochemical properties, poly (ADP-ribose) may play an active role in mediating the biological functions of PARPs.

Histones exhibit differential affinity for poly(ADP-ribose) (Wesierska-Gadek and Sauermann 1988; Panzeter et al. 1992; Realini and Althaus 1992; Malanga et al. 1998a), the hierarchy of binding being $\mathrm{H} 1>\mathrm{H} 2 \mathrm{~A}>\mathrm{H} 2 \mathrm{~B}=\mathrm{H} 3>\mathrm{H} 4$ (Panzeter et al. 1992). The interaction is for all of them far stronger and more specific than could be expected on the basis of electrostatic interactions. For instance, poly(ADP-ribose)-bound histones resist phenol partitioning, strong acids, detergents, and high salt concentrations (Panzeter et al. 1992). An additional element of specificity is the fact that protein basicity and (or) DNA binding ability are not sufficient to confer affinity for poly(ADP-ribose) (Panzeter et al. 1992). On the other hand, size and branching of (ADP-ribose) polymers are important determinants of binding, as branched polymers are a highly preferred target, followed by long linear molecules (Panzeter et al. 1992). These classes of polymers are also synthesized in vivo and their levels increase in response to DNA damage (Kanai et al. 1982; Alvarez-Gonzalez and Jacobson 1987; Malanga and Althaus 1994; Malanga and Farina 2000).

The amazingly high specificity of histone-poly(ADP-ribose) interactions could be explained by the discovery that binding only occurs at specific histone domains (C-terminus of histone $\mathrm{H} 1$ and N-terminal tails of core histones) (Panzeter et al. 1993) and, within such domains, only at distinct sequences that define, over a stretch of 20-26 amino acids, a highly homologous binding motif (Pleschke et al. 2000). These sequences involve a precisely spaced set of hydrophobic and basic species that by mutational analysis have been found to be critical for binding; the interaction is further strengthened by, but not absolutely dependent on, flanking arginines or lysines and a cluster of basic amino acids at the N-terminus (Pleschke et al. 2000; Gagné et al. 2003).

Screening of protein sequence databases with the polymerbinding consensus motif has led to the identification of a family of poly(ADP-ribose) interaction partners (Fig. 3). Many of these proteins are directly involved in the cellular response to DNA damage at the level of damage recognition and processing (i.e., XPA, XRCC1, MSH6, DNA ligase III, DNA polymerase $\varepsilon$ ) and (or) in later events responsible for cell cycle regulation-apoptosis (i.e., p53, p21, NF-kB, iNOS, DNA-PK, caspase-activated DNase). Heterogeneous nuclear ribonucleoproteins (Gagné et al. 2003), DNA methyltransferase-1 (Reale et al. 2005), DNA topoisomerases (Malanga and Althaus 2004), MARCKS (myristoylated-alaninerich-C-kinase-substrate), MRP (MARCKS-related protein) (Schmitz et al. 1998), and the centromeric proteins CENPA and CENPB (Saxena et al. 2002) also carry 1 or more poly (ADP-ribose)-binding motifs in their sequences. Other polymer-binding proteins, for which the binding sites have not been elucidated yet, include caspase 7 (Germain et al. 1999), the 20S proteasome (Mayer-Kuckuk et al. 1999), the telomere-binding protein TRF-2 (Dantzer et al. 2004), lamins (Gagné et al. 2003), and several other nuclear and nuclear matrix proteins (Malanga et al. 1998b); Malanga and Farina 2000).

As for histones, in all tested cases, poly(ADP-ribose) binding to target proteins has functional consequences on the domain functions, i.e., either inhibition or stimulation of domain activities. For instance, poly(ADP-ribose) prevents the binding to DNA of p53 or TRF-2, while it enhances degradation of oxidatively damaged histones by the $20 \mathrm{~S}$ proteasome. Caspase 7 affinity for poly(ADP-ribose) may explain its preference for poly(ADP-ribosyl)ated PARP-1 as a substrate, rather than for the native enzyme.

Because of the wide distribution of the polymer-binding sequence motif, widespread occurrence of PARP-dependent regulatory mechanisms can be expected. Thus, identification of more poly(ADP-ribose) protein partners may help elucidate new branches of cellular signaling pathways.

\section{Poly(ADP-ribose) binding "reprograms" domain functions of proteins}

How does polymer binding affect the function of target proteins? First, the binding of poly(ADP-ribose) to the polymerbinding consensus motif is very strong (Panzeter et al. 1992). Second, in almost all cases studied so far, the polymerbinding sequence overlaps with strategic functional domains in the target protein. For instance, in XRCC1 the poly(ADPribose)-binding site lies within the BRCT1 domain, situated between the binding sites of DNA polymerase $\beta$ and DNA ligase III (Pleschke et al. 2000). Thus, XRCC1 recruited via poly(ADP-ribose) at the site of damage is still able to interact with its protein partners to form a functional repair complex (Okano et al. 2003; El-Khamisy et al. 2003). Third, polymer binding may enhance and inhibit separate domain functions in the same protein (Malanga and Althaus 2004).

The tumor suppressor protein p53 is a particularly well studied example of protein function regulated by poly(ADPribose): the polymer-binding sites of p53 co-localize with the sequence-specific DNA binding domain (residues 153- 
Fig. 3. Protein targeting by poly(ADP-ribose): alignment of polymer binding sequences.

\begin{tabular}{|c|c|c|}
\hline \multirow[t]{2}{*}{ Target Proteins } & \multirow[t]{2}{*}{$\begin{array}{l}\text { SwissProt } \\
\text { Accession N }\end{array}$} & Binding Sequences \\
\hline & & hxbxhhbbhhb \\
\hline $\begin{array}{l}\text { H3 } 51-72 \\
\text { H4 }_{16-40} \\
\text { H2A }_{11-36} \\
\text { H2B }_{23-47}\end{array}$ & $\begin{array}{l}\mathrm{P} 16106 \\
\mathrm{P} 02304 \\
\mathrm{P} 02261 \\
\mathrm{P} 02278\end{array}$ & $\begin{array}{r}\text { IRRYQKSTELLIRKLPFQRLVR } \\
\text { KRHRKVLRDN IQGITKPAIRRLARR } \\
\text { RAKAKTRSSRAGLQFPVGRVHRLK } \\
\text { KKDGKKRKRSRKESYS I Y YYKVLKQ }\end{array}$ \\
\hline $\begin{array}{l}\text { p53156-181 } \\
\text { p53234-256 } \\
\text { p53329-351 } \\
\text { p21140-163 } \\
\text { NF-kB179-199 } \\
\text { iNOS505-525 } \\
\text { CAD } 148-169\end{array}$ & $\begin{array}{l}\text { P38936 } \\
\text { Q00653 } \\
\text { P35228 } \\
\text { O76075 }\end{array}$ & $\begin{array}{l}\text { RVRAMA I YKQSQHMTE- VVRRCPHHER } \\
\text { YNYMCNSSCMGGMNRRP ILT I I T } \\
\text { TLQIRGRERFEMFRELNEALELK } \\
\text { RKRRQTSMTDFYHSKRRL I FSKRK } \\
\text { KELKKVMDLS I VRLRFSAFLR } \\
\text { KRRPKRRE IPLKVLVKAVLFA } \\
\text { RFQSKSGYLRYSCESRIRSYLR }\end{array}$ \\
\hline $\begin{array}{l}\text { XP-A } 215-237 \\
\text { XRCC-1 } 379-400 \\
\text { DNA lig III } 12-34 \\
\text { DNA pol } \varepsilon 691-709 \\
\text { DNA-PKes } 2728-2752 \\
\text { MSH6295-317 } \\
\text { Ku70243-263 }\end{array}$ & $\begin{array}{l}\text { P23025 } \\
\text { P18887 } \\
\text { P49916 } \\
\text { Q07864 } \\
\text { P78527 } \\
\text { P52701 } \\
\text { P12956 }\end{array}$ & $\begin{array}{c}\text { KQKKFDKKVKELRRAVRSS VWKR } \\
\text { RIVRKEWVLDCHR-MRRRLPSRR } \\
\text { KRGTAGCKKCKEKIVK-GVCRIGK } \\
\text { KRRLADYCRKAYKKIHITK } \\
\text { KVARKRKRMVTGNSLRKSSRK } \\
\text { RRRFMRDQEKLSLMYARKGVAEQKR } \\
\text { RKVRAKETRKRALSR-LKLKLNK }\end{array}$ \\
\hline MARCKS $151-175$ & P29966 & KKKKKRFSFKKSFKLSGFSFKKNKK \\
\hline TERT $962-983$ & 014746 & RGFKAGRNMRRKLFGVLRLKCH \\
\hline hnRNP A299-120 & P22626 & REESGKPGAHVTVKKLFVGG IK \\
\hline $\begin{array}{l}\text { topo I } 261-280 \\
\text { topo I } 532-551 \\
\text { topo I } 669-688 \\
\text { *topo II } \alpha 971-990\end{array}$ & P11387 & $\begin{array}{l}\text { AKMLDHEYTTKEIFRKNFFK } \\
\text { KDS I RYYNKVPVEKRVFKNL } \\
\text { KADAKVMKDAKTKKVVESKK } \\
\text { KMTEEKLAEAERVGLHKVFK }\end{array}$ \\
\hline $\begin{array}{l}\text { CENPA } 57-74 \\
\text { CENPB } 583-597\end{array}$ & $\begin{array}{l}\text { O35216 } \\
\text { P27790 }\end{array}$ & $\begin{array}{r}\text { RKKPFSMVVREICEKFS R } \\
R K N H A R Q A G V R G L G H\end{array}$ \\
\hline
\end{tabular}

See text for references.

* Malanga and Althaus, unpublished

181 and 231-256) and with the C-terminal domain (amino acids 326-351), containing a nuclear localization signal, a nuclear export signal, and the tetramerization domain (Malanga et al. 1998c. In vitro studies have demonstrated that poly (ADP-ribose) binding at the target sites is able to block (or reverse) p53 association both with ssDNA and, at higher concentrations, with a ds-oligonucleotide containing a p53 consensus sequence. Thus, p53 may differentially respond to poly(ADP-ribose) induced by DNA damage. At low levels of DNA damage, a few polymers clustered on PARP-1 and PARP-2 could block the ssDNA binding function and favour the transcriptional activity of p53. Conversely, high amounts of poly(ADP-ribose), associated with excessive DNA damage and massive $\mathrm{NAD}^{+}$consumption, could inhibit p53 activities completely and thus contribute to directing cells towards caspase-independent programmed cell death (Yu et al. 2002; Alano et al. 2004) or necrosis (Berger 1985). Hence, poly (ADP-ribose) metabolism might operate as a dual mechanism that activates p53-dependent and p53-independent pathways to ensure either repair or disposal of cells with compromised genome functions.

Activation of p53 has been demonstrated even in the absence of DNA damage (Hupp et al. 1995). Microinjection of cells with an antibody targeting the C-terminal part of the protein suffices to activate p53-dependent gene expression. Thus, PARP-1-bound polymers extending from DNA breakage sites might also directly activate p53 by neutralizing the inhibitory influence of the C-terminal domain on p53 transcriptional activity.

Another possibility is that poly(ADP-ribose) contributes to p53 stabilization. A functional link between PARP-1 and p53 is suggested by in vitro and in vivo observations showing that the 2 proteins form complexes. This depends on $\mathrm{p} 53$ phosphorylation and involves the N-terminal and central domains of PARP-1 and the central and C-terminal domains of p53 (Wesierska-Gadek et al. 2003a, 2003b). Furthermore, basal p53 levels are significantly reduced in Chinese hamster cell lines with defective poly(ADP-ribosyl)ation (Whitacre et al. 1995) and in embryonic fibroblasts from PARP-1 knockout mice (Wesierska-Gadeket al. 2003a, 2003b). In the latter case, p53 depletion could be counteracted by treatment with leptomycin B, an inhibitor of nuclear export. This points to an impairment of p53 basal stability rather than reduced p53 gene expression in the absence of PARP-1. Thus, in DNA- 
Fig. 4. Topo I targeting by poly(ADP-ribose). Top: domain structure of topo I; white boxes with vertical lines locate the poly(ADP-ribose) binding sites. NTD, N-terminal domain; LD, linker domain; CTD, C-terminal domain. Bottom: schematic view of topo I catalytic cycle. The effects of poly(ADP-ribose) on individual steps of the cycle are indicated in bold.

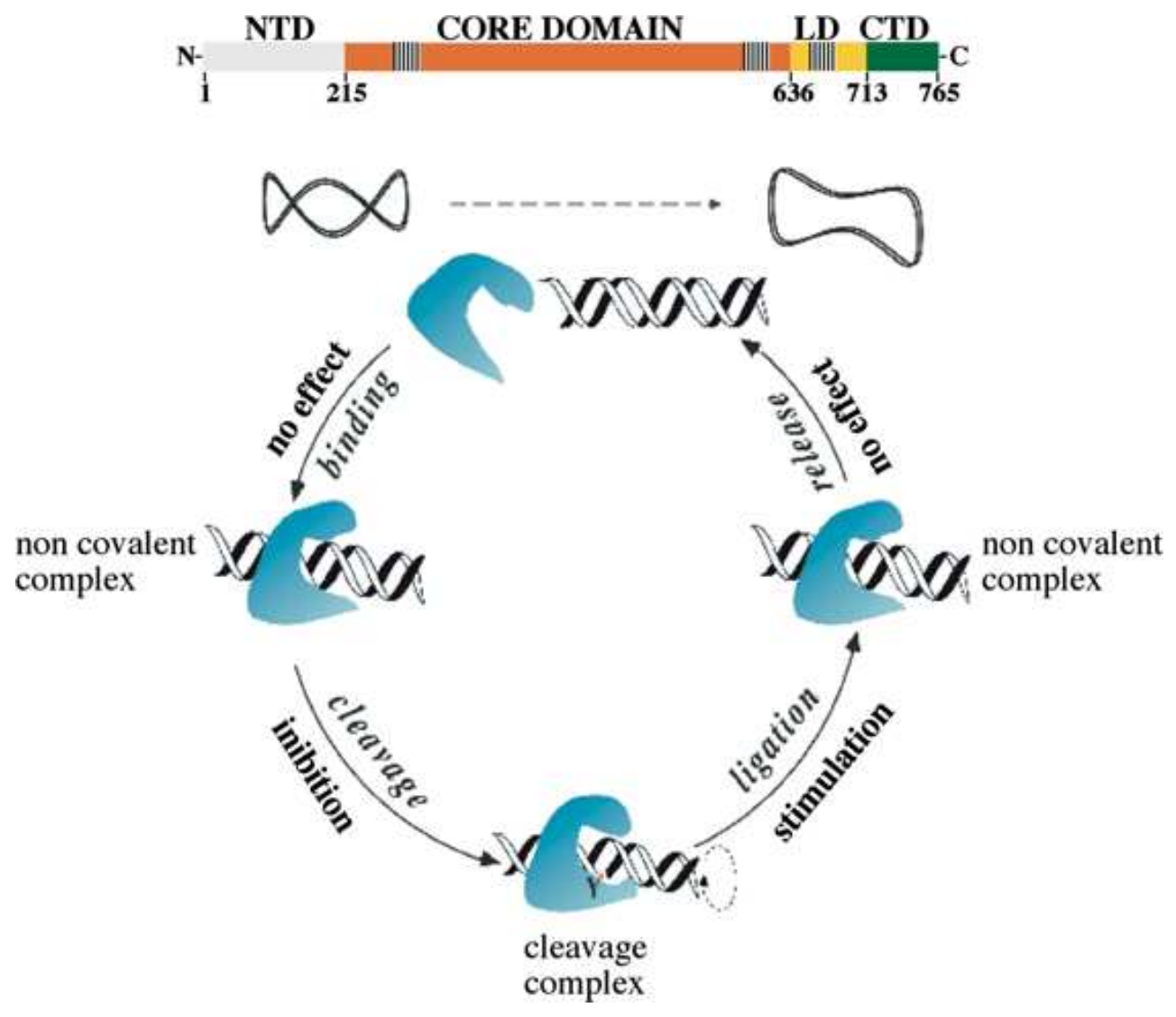

damaged cells, automodified PARP-1 may regulate the nucleocytoplasmic shuttling of p53 such that larger amounts of the protein accumulate in the nucleus.

Another example of protein targeting by poly(ADP-ribose) and reprogramming of domain functions is DNA topoisomerase I (topo I). Topo I is involved in the control of DNA supercoiling, allowing topological changes that are necessary for DNA transactions (Wang 2002). In the course of the reaction, eukaryotic topo I cleaves 1 strand of the DNA substrate and remains covalently bound to it through a $3^{\prime}$ phospho-tyrosine linkage (cleavage complex). After DNA rotation around the intact strand, the DNA backbone integrity is restored, and the enzyme is released in a reverse transesterification reaction, with the 5'-hydroxyl end of the cleaved strand acting as a nucleophile (Fig. 4).

Under normal conditions, DNA religation is fast; however, when acting on damaged DNA, topo I may get trapped in the complex with nicked DNA (stalled topo I) (Pourquier and Pommier 2001). Stalled topo I is a threat to genomic stability as it can be converted into DNA strand breaks and irreversible enzyme-DNA crosslinks upon collision with replication forks or elongating RNA polymerases (topo Iinduced DNA damage). The cytotoxic potential of such lesions is underscored by the fact that stabilization of topo I cleavage complexes is the mechanism of action of a class of anticancer drugs, including the natural alkaloid camptothecin (CPT) and its synthetic derivatives (Kohn and Pommier 2000). In vitro, both the forward and reverse transesterification re- actions can be modulated by poly(ADP-ribose) through physical interactions with topo I (Malanga and Althaus 2004). DNA cleavage is, in fact, inhibited, and the religation activity of the enzyme blocked in a ternary complex with nicked DNA and CPT is resumed in the presence of poly(ADPribose). Thus, in living cells, PARP-bound poly(ADP-ribose) might have a protective effect against secondary topo I-induced DNA damage by preventing the enzyme from starting its catalytic cycle on damaged DNA, as well as by reactivating stalled topo I and inducing rapid resealing of the cleaved DNA strand. On the other hand, in the in vitro system, polymers do not interfere with topo I noncovalent binding to DNA (Fig. 4).

The composite effects of poly(ADP-ribose) on the catalytic cycle of topo I result from reprogramming-specific domain functions. Three poly(ADP-ribose) binding sites overlap with structurally and functionally important domains. Two sequences, comprising amino acids 261-280 and 532-550, are in the core DNA binding domain but at opposite sites of the clamp formed by the enzyme around DNA; a third polymerbinding site (sequence 669-688) is in the linker domain. The latter connects the DNA binding and C-terminal domains and has a regulatory role on the overall reaction, slowing down the religation step and thereby facilitating DNA relaxation (Stewart et al. 1998, 1999). Mapping the poly (ADPribose)-binding sites into the published crystal structure of human topo I (Redinbo et al. 1998) reveals that the polymerbinding regions have no primary role in the DNA binding of 
topo I. This may explain why poly (ADP-ribose), while interacting with the free enzyme, does not affect topo IDNA noncovalent complexes. On the other hand, the sequence comprising amino acids $532-550$ is located in core subdomain III, which largely contributes to the formation of the catalytic site: binding of poly (ADP-ribose) at this site likely causes the strong inhibition of the DNA cleavage reaction. The cap region of topo I (residues 175-433), which includes the poly (ADP-ribose)-binding sequence 261-280, is also essential for DNA cleavage (Yang and Champoux 2002).

Finally, targeting of the linker domain, which has been shown to play a fundamental role in stabilizing ternary complexes of enzyme-DNA-drug (Staker et al. 2002), may be responsible for the reactivation of CPT-inhibited topo I. In this context, it is noteworthy that deletion of the linker domain, either total (Stewart et al. 1999) or partial (Ireton et al. 2000) or even a single amino acid substitution (Fiorani et al. 2003), affects the rate of religation and makes topo I insensitive to CPT, a phenotype that is also observed when the native enzyme acts in the presence of poly(ADP-ribose).

\section{Concluding remarks}

In conclusion, the available data support a model in which poly(ADP-ribose) synthesis on PARP-1 and PARP-2 following genotoxic insult by chemicals (alkylating or oxidizing agents) or $\gamma$-radiation serves as a signal transduction mechanism for DNA strand breaks. With their polymeric arms, activated PARPs may reach out to bind neighbouring proteins and affect their functions. By reversible automodification PARP-1 and PARP-2 may rapidly change their partner profile and thus assemble different functional complexes, depending on the differential requirements of the DNA-damage signal network. The primary effects of PARP automodification may be local, involving changes in chromatin architecture (by poly ADP-ribose targeting of histones), recruitment of the BER machinery (by specific binding of XRCC1 and (or) other DNA repair proteins), or removal of damaged nuclear proteins (by direct activation of the nuclear 20S proteasome). Inhibition of topo I activity on damaged DNA and reactivation of the stalled enzyme in the vicinity of DNA lesions may be part of this early attempt to restore genomic integrity. Secondarily, if the extent of damage exceeds the capacity of the repair systems, the status of genomic stress can be signaled to downstream effectors of the DNA damage response and initiate cell death pathways. As well, the change in DNA topology caused by local modulation of topo I activity may, itself, be a signal of damaged DNA that is transmitted along the chromatin fiber.

Another aspect that should not be overlooked when regulation of chromatin functions is considered is the fact that PARP-1 can build ADP-ribose polymers not only on itself but also on other proteins in a heteromodification reaction. Several nuclear proteins, primarily histones but also enzymes (DNA polymerases, RNA polymerases, topoisomerases, nucleases) and transcription factors (p53, Fos, TFIIF, YY-1), may serve as covalent acceptors of poly(ADP-ribose) (D'Amours et al. 1999). Although hetero(ADP-ribosyl)ation entails a limited fraction of the cellular poly(ADP-ribosyl) ation capacity, it may play a role in DNA repair as well as in other nuclear processes. For instance, it has been estimated that $0.1 \%$ of cellular DNA topoisomerase I is covalently ADP-ribosylated under homeostatic conditions in mouse epidermal cells JB6, and this fraction increases substantially, albeit transiently, following DNA damage (Krupitza and Cerutti 1989).

A close correlation between poly(ADP-ribosyl)ation, chromatin structure, and programmed gene expression is suggested by several lines of evidence (D'Amours et al. 1999; Rouleau et al. 2004) and has found recent corroboration in the work of Tulin and Spradling (2003) on Drosophila polytene chromosomes. Covalent histone modification, which involves essentially short ADP-ribose oligomers (Boulikas et al. 1990; D'Erme et al. 1996; Faraone-Mennella et al. 1999), may destabilize inter- and intranucleosomal DNA-protein interactions, as has been shown for acetylation, phosphorylation, and ubiquitination (Ausió et al. 2001). In fact, ADPribosylation of histone $\mathrm{H} 1$ and core histones has been demonstrated to cause relaxation of polynucleosomal preparations and partial unfolding of mononucleosomes respectively (Rouleau et al. 2004). Oligo(ADP-ribosyl)ation of histones and other proteins might also cooperate with other post-translational modifications (Malik and Smulson 1984; Boulikas 1990) (and with PARP automodification) to establish altered chromatin structures and (or) to modulate proteinprotein interactions in multiprotein complexes, allowing finetuning of regulated gene expression.

In the context of DNA repair, a low level of histone oligo (ADP-ribosyl)ation might be favoured by the high poly (ADP-ribose) turnover conditions at the site of DNA strand breakage (Thomassin et al. 1992) and persist after the strand break has been resealed and PARP automodification has been reversed. An attractive possibility is that (ADP-ribosyl)ated histones may mark domains in which DNA has undergone repair and cooperate with other epigenetic modifications to promote the recruitment of remodeling complexes and restore structural integrity up to the chromatin level.

\section{Acknowledgements}

The experimental work described in this review was funded by grants from the Swiss National Science Foundation to F.R.A.

\section{References}

Alano, C.C., Ying, W., and Swanson, R.A. 2004. Poly(ADP-ribose) polymerase- 1 mediated cell death in astrocytes requires $\mathrm{NAD}^{+}$ depletion and mitochondrial permeability transition. J. Biol. Chem. 279: $18895-18902$.

Althaus, F.R., Kleczkowska, H.E., Malanga, M., Muntener, C.R., Pleschke, J.M., Ebner, M, and Auer, B. 1999. Poly ADP-ribosylation: a DNA break signal mechanism. Mol. Cell. Biochem. 193: $5-11$.

Alvarez-Gonzalez, R., and Jacobson, M.K. 1987. Characterization of polymers of adenosine diphosphate ribose generated in vitro and in vivo. Biochemistry, 26: 3218-3224.

Alvarez-Gonzalez, R., and Althaus, F.R. 1989. Poly(ADP-ribose) catabolism in mammalian cells exposed to DNA-damaging agents. Mutat. Res. 218: 67-74.

Amé. J.C., Rolli V., Schreiber, V., Niedergang,C., Apiou, F., Decker, P. et al. 1999. PARP-2, a novel mammalian DNA-damage dependent poly(ADP-ribose) polymerase. J. Biol. Chem. 274: 17860-17868. 
Amé, J.C., Spenlehauer, C., and de Murcia, G. 2004. The PARP superfamily. Bioessays, 26: 882-893.

Audebert, M., Salles, B., and Calsou, P. 2004. Involvement of PARP-1 and XRCC1/DNA ligase III in an alternative route for double-strand breaks rejoining. J. Biol. Chem. 279: 55117-55126.

Ausió, J, Abbott, D.W., Wang, X., and Moore, S.C. 2001. Histone variants and histone modifications: a structural perspective. Biochem. Cell Biol. 79: 693-708.

Berger, N.A. 1985. Poly(ADP-ribose) in the cellular response to DNA damage. Radiat. Res. 101: 4-15.

Bouchard, V.J., Rouleau, M., and Poirier, G.G. 2003. PARP-1, a determinant of cell survival in response to DNA damage. Exp. Hematol. 31: 446-454.

Boulikas, T. 1990. Poly(ADP-ribosylated) histones in chromatin replication. J. Biol. Chem. 265: 14638-14647.

Caldecott, K.W. 2003. XRCC1 and DNA strand break repair. DNA Repair, 2: 955-969.

Chiarugi, A. 2002. Poly(ADP-ribose) polymerase: killer or conspirator? The "suicide hypothesis" revisited. Trends Pharmacol. Sci. 23: 122-129.

Cortes, U., Tong, W.M., Coyle, D. L., Meyer-Ficca, M.L., Meyer, R.G., Petrilli, V. et al. 2004. Depletion of the 110 kilodalton isoform of poly(ADP-ribose) glycohydrolase increases sensitivity to genotoxic and endotoxic stress in mice. Mol. Cell. Biol. 24: 7163-7178.

D’Amours, D., Desnoyers, S., D’Silva, I., and Poirier, G.G. 1999. Poly(ADP-ribosyl)ation reactions in the regulation of nuclear functions. Biochem. J. 342: 242-268.

Dantzer, F., de la Rubia, G., Ménissier-de Murcia, J., Hostomsky, Z., de Murcia, G., and Schreiber, V. 2000. Base excision repair is impaired in mammalian cells lacking poly(ADP-ribose) polymerase-1. Biochemistry, 39: 7559-7569.

Dantzer, F., Giraud-Panis, M.J., Jaco, I., Amé, J.C., Schultz, I., Blasco, M. et al. 2004. Functional interaction between poly (ADP-ribose) polymerase-2 (PARP-2) and TRF2: PARP activity negatively regulates TRF2. Mol. Cell. Biol. 24: 1595-1607.

Davidovic, L., Vodenicharov, M., Affar, E.B., and Poirier, G.G. 2001. Importance of poly(ADP-ribose) glycohydrolase in the control of poly(ADP-ribose) metabolism. Exp. Cell Res. 268: $7-13$.

de Capoa, A., Febbo, F.R., Giovannelli, F., Niveleau, A., Zardo, G., Marenzi, S., and Caiafa, P. 1999. Reduced levels of poly(ADPribosyl)ation result in chromatin compaction and hypermethylation as shown by cell-by-cell computer-assisted quantitative analysis. FASEB J. 13: 89-93.

D’Erme. M., Zardo, G., Reale, A., and Caiafa, P. 1996. Cooperative interactions of oligonucleosomal DNA with the H1e variant and its poly(ADP-ribosyl)ated isoform. Biochem J 316: 475480.

de Murcia, G., and Menissier-de Murcia, J. 1994. Poly(ADP-ribose) polymerase: a molecular nick sensor. Trends Biochem. Sci. 19: $172-176$.

Ehrenhofer-Murray, A.E. 2004. Chromatin dynamics at DNA replication, transcription and repair. Eur. J. Biochem. 271: 23352349.

El-Khamisy, S.F, Masutani, M., Suzuki, H., and Caldecott, K.W. 2003. A requirement for PARP-1 for the assembly or stability of XRCC1 nuclear foci at sites of oxidative DNA damage. Nucleic Acids Res. 31: 5526-5533.

Faraone-Mennella, M.R., De Lucia, F., Gentile, N., Quesada, P., and Farina, B. 1999. In vitro poly(ADP-ribosyl)ated histones $\mathrm{H} 1 \mathrm{a}$ and H1t modulate rat testis chromatin differentially. J. Cell. Biochem. 76: 20-29.

Fiorani, P., Bruselles, A., Falconi, M., Chillemi, G., Desideri, A., and Benedetti, P. 2003. Single mutation in the linker domain confers protein flexibility and camptothecin resistance to human topoisomerase I. J. Biol. Chem. 278: 43268-43275.

Gagné, J.P., Hunter, J.M., Labrecque, B., Chabot, B., and Poirier, G.G. 2003. A proteomic approach to the identification of heterogeneous nuclear ribonucleoproteins as a new family of poly (ADP-ribose)-binding proteins. Biochem. J. 371: 331-340.

Germain, M., Affar, E.B., D'Amours, D., Dixit, V.M., Salvesen, G.S., and Poirier, G.G. 1999. Cleavage of automodified poly (ADP-ribose) polymerase during apoptosis. J. Biol. Chem. 274: 28379-28384.

Hassa, P.O., and Hottiger, M.O. 2002. The functional role of poly (ADP-ribose) polymerase 1 as novel coactivator of NF-kB in inflammatory disorders. Cell. Mol. Life Sci. 59: 1-20.

Hong, S.J., Dawson, T.M., and Dawson, V.L. 2004. Nuclear and mitochondrial conversations in cell death: PARP-1 and AIF signaling. Trends Pharmacol. Sci. 25: 259-264.

Hupp, T.R., Sparks, A., and Lane, D.P. 1995. Small peptides activate the latent sequence-specific DNA binding function of p53. Cell, 83: 237-245.

Ireton, G.C., Stewart, L., Parker, L.H., and Champoux, J.J. 2000. Expression of human topoisomerase I with a partial deletion of the linker region yields monomeric and dimeric enzymes that respond differently to camptothecin. J. Biol. Chem. 275: 2582025830.

Kanai, M., Miwa, M., Kuchino, Y., and Sugimura, T. 1982. Presence of branched portion in poly(adenosine diphospate ribose) in vivo. J. Biol. Chem. 257: 6217-6223.

Kastan, M.B., and Bartek, J. 2004. Cell-cycle checkpoints and cancer. Nature (London), 432: 316-323.

Koh, D.W., Lawler, A.M., Poitras, M.F., Sasaki, M., Wattler, S., Nehls, M.C. et al. 2004. Failure to degrade poly(ADP-ribose) causes increased sensitivity to cytotoxicity and early embryonic lethality. Proc. Natl. Acad. Sci. U.S.A. 101: 17669-17704.

Kohn, K.W., and Pommier, Y. 2000. Molecular and biological determinants of the cytotoxic action of camptothecins. Ann. N. Y. Acad. Sci. 922: 11-26.

Kraus, W.L., and Lis, J.T. 2003. PARP goes transcription. Cell, 113: 677-683.

Krupitza, G., and Cerutti, P. 1989. ADP-ribosylation of ADPRtransferase and topoisomerase I in intact mouse epidermal cells JB6. Biochem. 28: 2034-2040.

Lane, D.L., and Hupp, T.R. 2003. Drug discovery and p53. DDT. 8: 347-355.

Le Cam, E., Fack, F., Ménissier-de Murcia, J., Cognet, J.A., Barbin, A., Sarantoglou, V. et al. 1994. Conformational analysis of a 139 base-pair DNA fragment containing a single-stranded break and its interaction with human poly(ADP-ribose) polymerase. J. Mol. Biol. 235: 1062-1071.

Le Page, F., Schreiber, V., Dhérin, C., de Murcia, G., and Boiteux, S. 2003 Poly(ADP-ribose) polymerase-1 (PARP-1) is required in murine cell lines for base excision repair of oxidative DNA damage in the absence of DNA polymerase $\beta$. J. Biol. Chem. 278: 18471-18477.

Leppard, J.B., Dong, Z., Mackey, Z.B,., and Tomkinson, A.E. 2003. Physical and functional interaction between DNA ligase III $\alpha$ and poly(ADP-ribose) polymerase 1 in DNA single-strand break repair. Mol. Cell. Biol. 23: 5919-5927.

Malanga, M., and Althaus, F.R. 1994. Poly(ADP-ribose) molecules formed during DNA repair in vivo. J. Biol. Chem. 269: 1769117696.

Malanga, M., and Althaus, F.R. 2004. Poly(ADP-ribose) reactivates stalled DNA topoisomerase I and induces DNA strand break resealing. J. Biol. Chem. 279: 5244-5248. 
Malanga, M., and Farina, B. 2000. Noncovalent binding of poly (ADP-ribose) to nuclear matrix proteins: developmental changes and tissue specificity. Biol. Chem. 381: 1047-1053.

Malanga, M., Atorino, L., Tramontano, F., Farina, B., and Quesada, P. 1998a. Poly(ADP-ribose) binding properties of histone H1 variants. Biochim. Biophys. Acta, 1399: 154-160.

Malanga, M., Kleczkowska, H.E., Althaus, F.R. 1998b. Selected nuclear matrix proteins are targets for poly(ADP-ribose)-binding. J. Cell. Biochem. 70: 596-603.

Malanga, M., Pleschke, J., Kleczkowska, H.E., and Althaus, F.R. 1998c. Poly(ADP-ribose) binds to specific domains of p53 and alters its DNA binding functions. J. Biol. Chem. 273: 1183911848.

Malik, N., and Smulson, M.A. 1984. Relationship between nuclear poly(adenosine diphosphate ribosylation) and acetylation posttranslational modifications. Biochem. 23: 3721-3725.

Masson, M., Niedergang, C., Schreiber, V., Muller, S., Menissier-de Murcia, J., and de Murcia, G. 1998. XRCC1 is specifically associated with poly(ADP-ribose) polymerase and negatively regulates its activity following DNA damage. Mol. Cell. Biol. 18: 3563-3571.

Masutani, M., Nozaki, T., Nakamoto, K., Nakagama, H., Suzuki, H. Kasuoka,O. et al. 2000. The response of Parp knockout mice against DNA damaging agents. Mutat. Res. 462: 159-166.

Mathis, G., and Althaus, F.R. 1987. Release of core DNA from nucleosomal core particles following (ADP-ribose)n-modification in vitro. Biochem. Biophys. Res. Commun. 143: 1049-1057.

Mathis, G., and Althaus, F.R. 1990. Uncoupling of DNA excision repair and nucleosomal unfolding in poly(ADP-ribose)-depleted mammalian cells. Carcinogenesis, 11: 1237-1239.

Mayer-Kuckuk, P., Ullrich, O., Ziegler M., Grune, T., and Schweiger, M. 1999. Functional interaction of poly(ADP-ribose) with the 20S proteasome in vitro. Biochem. Biophys. Res. Commun. 259: 576-581.

Mendoza-Alvarez, H., and Alvarez-Gonzalez, R. 1993. Poly(ADPribose) polymerase is a catalytic dimer and the automodification reaction is intermolecular. J. Biol. Chem 268: 22575-22580.

Ménissier-de Murcia, J., Ricoul, M., Tartier, L., Niedergang, C., Huber, A., Dantzer, F. et al. 2003. Functional interaction between PARP-1 and PARP-2 in chromosome stability and embryonic development in mouse. EMBO J. 22: 2255-2263.

Meyer-Ficca, M.L., Meyer, R.G., Coyle, D.L., Jacobson, E.L., and Jacobson, M.K. 2004. Human poly(ADP-ribose) glycohydrolase is expressed in alternative splice variants yielding isoforms that localize to different cell compartments. Exp. Cell Res. 297: 521532.

Minaga, T., and Kun, E. 1983. Probable helical conformation of poly(ADP-ribose). J. Biol. Chem. 258: 5726-5730.

Miwa, M., Kato, M., Iijima, H., Tanaka, Y., Kondo,T., Kawamitsu, H. et al. 1983. Poly(ADP-ribose): structure, quantification, and biological significance. In ADP-ribosylation, DNA repair and cancer. Edited by M. Miwa et al. Jpn. Sci. Soc. Press, Tokyo. pp. 27-37.

Okano, S., Lan, L., Caldecott, K.W., Mori, T., and Yasui, A. 2003. Spatial and temporal cellular responses to single-strand breaks in human cells. Mol. Cell. Biol. 23: 3974-3981.

Panzeter, P.L., and Althaus, F.R. 1994. DNA strand break-mediated partitioning of poly(ADP-ribose) polymerase function. Biochemistry, 33: 9600-9605.

Panzeter, P.L, Realini, C., and Althaus, F.R. 1992. Noncovalent interactions of poly(adenosine diphosphate ribose) with histones. Biochem. 31: 1379-1385.

Panzeter, P.L., Zweifel, B., Malanga, M., Waser, S.H., Richard,
M.C., and Althaus, F.R. 1993. Targeting of histone tails by poly (ADP-ribose). J. Biol. Chem. 268: 17662-17664.

Pleschke, J.M., Kleczkowska, H.E., Strom, M., and Althaus, F.R. 2000. Poly(ADP-ribose) binds to specific domains in DNA damage checkpoint proteins. J. Biol. Chem. 275: 40 974-40 980.

Pourquier, P., and Pommier, Y. 2001. Topoisomerase I-mediated DNA damage. Adv. Cancer Res. 80: 189-216.

Reale, A., De Matteis, G., Galleazzi, G., Zampieri, M., and Caiafa, P. 2005. Modulation of DNMT1 activity by ADP-ribose polymers. Oncogene, 24: 13-19.

Realini, C., and Althaus, F.R. 1992. Histone shuttling by poly (ADP-ribosyl)ation. J. Biol. Chem. 267: 18858-18865.

Redinbo, M.R., Stewart, L., Kuhn, P., Champoux J.J., and Hol, W.G.J. 1998. Crystal structure of human topoisomerase I in covalent complexes with DNA. Science, 279: 1504-1513.

Rolli, V., Ruf, A., Augustin, A., Schulz, G.E., Ménissier-de Murcia, J., and de Murcia, G. 2000. Poly(ADP-ribose) polymerase: structure and function. In From DNA damage and stress signaling to cell death. Poly ADP-ribosylation reactions. Edited by G. de Murcia and S. Shall. Oxford University Press. pp. 35-79.

Rouleau, M., Aubin, R.A., and Poirier, G,G. 2004. Poly(ADPribosyl)ated chromatin domains: access granted. J. Cell Science, 117: 815-825.

Rudat, V., Bachmann, N., Kupper, J.H., and Weber, K J. 2001. Overexpression of the DNA-binding domain of poly(ADP-ribose) polymerase inhibits rejoining of ionizing radiation-induced DNA double-strand breaks. Int. J. Radiat. Biol. 77: 303-307.

Saxena, A., Saffery, R., Wong, L.H., Kalitsis, P., and Choo, K.H. 2002. Centromere proteins Cenpa, Cenpb, and Bub3 interact with poly(ADSP-ribose)polymerase-1 protein and are poly (ADP-ribosyl)ated. J. Biol. Chem. 277: 26921-26926.

Schmitz, A.A.P., Pleschke, J.M, Kleczkowska, H.E, Althaus, F.R., and Vergères, G. 1998. Poly(ADP-ribose) modulates the properties of MARCKS proteins. Biochem. 37: 9520-9527.

Schreiber, V., Amé, J.C., Dollé, P., Schultz, I., Rinaldi, B., Fraulob, V. et al. 2002. Poly(ADP-ribose) polymerase-2 (PARP-2) is required for efficient base excision DNA repair in association with PARP-1 and XRCC-1. J. Biol. Chem. 277: 23028-23036.

Scovassi, A.I. 2004. Mitochondrial poly(ADP-ribosylation): from old data to new perspectives. FASEB J. 18: 1487-1488.

Simonin, F., Hofferer, L., Panzeter, P.L., Muller, S., de Murcia, G., and Althaus F.R. 1993. The carboxyl-terminal domain of human poly(ADP-ribose) polymerase. Overproduction in Escherichia coli, large scale purification and characterization. J. Biol. Chem. 278: 13454-13461.

Shall, S., and de Murcia, G. 2000. Poly(ADP-ribose) polymerase-1: what have we learned from the deficient mouse model? Mutation Res. 460: $1-15$.

Staker, B.L., Hjerrild, K., Feese, M.D., Behnke, C.A., Burgin, A.B., Jr., and Stewart, L. 2002. The mechanism of topoisomerase I poisoning by a camptothecin analog. Proc. Natl. Acad. Sci. U.S.A. 99: $15387-15392$.

Stewart, L., Redinbo, M.R., Qiu, X., Hol, W.G.J., and Champoux, J.J. 1998. A model for the mechanism of human topoisomerase I. Science (Wash.), 279: 1534-1541.

Stewart, L., Ireton, G.C., and Champoux, J.J. 1999. A functional linker in human topoisomerase I is required for maximum sensitivity to camptothecin in a DNA relaxation assay. J. Biol. Chem. 274: 32950-32960.

Thomassin, H., Ménard, L., Hengartner, C., Kirkland, J.B., and Poirier G.G. 1992. Poly(ADP-ribosyl)ation of chromatin in an in-vitro poly(ADP-ribose)-turnover system. Biochim. Biophys. Acta, 1137: 171-181.

Tulin, A., and Spradling, A. 2003. Chromatin loosening by poly 
(ADP)-ribose polymerase (PARP) at Drosophila puff loci. Science (Wash.), 299: 560-562.

Ullrich, O., and Grune, T. 2001 Proteasomal degradation of oxidatively damaged endogenous histones in K562 human leukemic cells. Free Radical Biol. Med. 31: 887-893.

Valenzuela, M.T., Guerrero, R., Nunez, M.I., Ruiz De Almodovar, J.M., Sarker, M., de Murcia, G. et al. 2002. PARP-1 modifies the effectiveness of p53-mediated DNA damage response. Oncogene, 21: 1108-1116.

Veuger, S.J., Curtin, N.J., Richardson, C.J., Smith, G.C.M., and Durkacz, B.W. 2003. Radiosensitization and DNA repair inhibition by the combined use of novel inhibitors of DNA-dependent protein kinase and poly(ADP-ribose) polymerase. Cancer Res. 63: 6008-6015.

Veuger, S.J., Curtin, N.J., Smith, G.C.M,., and Durkacz, B.W. 2004. Effects of novel inhibitors of poly(ADP-ribose) polymerase-1 and the DNA-dependent protein kinase on enzyme activities and DNA repair. Oncogene, 23: 7322-7329.

Wang, J.C. 2002. Cellular roles of DNA topoisomerases:a molecular perspective. Nature Rev. Mol. Cell. Biol. 3: 430-440.

Wang, X., Ohnishi, K., Takahashi, A., and Ohnishi, T. 1998. Poly (ADP-ribosyl)ation is required for p53-dependent signal transduction induced by radiation. Oncogene, 17: 2819-2825.

Wieler, S., Gagné, J.P., Vaziri,H., Poirier, G.G., and Benchimol, S. 2003. Poly(ADP-ribose) polymerase- 1 is a positive regulator of the p53-mediated G1 arrest response following ionizing radiation. J. Biol. Chem. 278: 18914-18921.
Wesierska-Gadek, J., and Sauermann, G. 1988. The effect of poly (ADP-ribose) on interactions of DNA with histones $\mathrm{H} 1, \mathrm{H} 3$ and H4. Eur. J. Biochem. 173: 675-679.

Wesierska-Gadek, J., Wojciechowski, J., and Schmid, G. $2003 a$. Phosphorylation regulates the interaction and complex formation between wt p53 protein and PARP-1. J. Cell. Biochem. 89: 1260-1284.

Wesierska-Gadek, J., Wojciechowski, J., Schmid, G. 2003b. Central and carboxy-terminal regions of human p53 protein are essential for interaction and complex formation with PARP-1. J. Cell. Biochem. 89: 220-232.

Whitacre, C.M., Hashimoto, H., Tsai, M.L., Chatterjee, S., Berger, S.J. and Berger N.A. 1995. Involvement of poly(ADP-ribose) metabolism in p53 regulation and its consequences. Cancer Res. 55: 3697-3701.

Yang, Z., and Champoux, J.J. 2002. Reconstitution of enzymatic activity by the association of the cap and catalytic domains of human topoisomerase I. J. Biol. Chem. 277: 30815-30823.

Yu, S.W., Wang, H., Poitras, M.F., Coombs, C., Bowers, W.J., Federoff, H.J. et al. 2002. Mediation of poly(ADP-ribose) polymerase-1-dependent cell death by apoptosis-inducing factor. Science (Wash.), 297: 259-263.

Zahradka, P., and Ebisuzaki, K. 1982. A shuttle mechanism for DNA-protein interactions. The regulation of poly(ADP-ribose) polymerase. Eur. J. Biochem. 127: 579-585. 